\title{
Editorial
}

\section{PUBLICA O PERECE: PARADIGMA DEL FRAUDE CIENTÍFICO}

La evaluación y promoción académica, internacionalmente radica en tres puntos básicos: la investigación, la docencia y la extensión. En Chile, en general, rigen los mismos conceptos y no se concibe una Universidad sin investigación (1-4), las que para su reconocimiento, deben estar publicadas, especialmente, en revistas indizadas por el Institute for Scientific Information (ISI).

Las publicaciones científicas pasan a ser los principales requisitos para la promoción académi$\mathrm{ca}$, para conseguir fondos concursables para investigación (5), o para el reconocimiento de sus pares. Los médicos, no somos una excepción a estas contingencias, que es vista por muchos como una gran presión, estableciéndose así el paradigma de "publica o perece" $(6,7)$. Esto hace posible que surja el fraude científico como la invención, la manipulación de datos, las duplicaciones, las redundancias, el plagio, las falsas autorías, los conflictos de intereses, la no publicación de resultados negativos, etc., graves faltas establecidas por el Comité Internacional de Directores de Revistas Médicas (8).

Los encargados de evaluar los antecedentes académicos, no siempre consideran el aporte de las investigaciones, sino la cantidad de publicaciones, las revistas o el factor impacto de ellas (9). Habitualmente no disponen del tiempo suficiente para analizar los artículos de los candidatos, debido a que los procesos de promoción académica, muchas veces son grupales y comparativos entre ellos, abriendo así las posibilidades de malas prácticas curriculares.

El Comité Internacional de Directores de Revistas Médicas, establece en el Editor Jefe de la revista, toda la responsabilidad de su contenido, el que debe velar por que sea fidedigna, que cumpla con los estándares éticos y los objetivos establecidos en su declaración de principios. Cuando el fraude es detectado en el proceso de revisión, este se detiene y los autores son informados de la falta, como también sus autoridades académicas. Si el fraude es detectado cuando ya se ha producido la publicación, los editores deben comunicarla a los lectores en el número más próximo de la revista, y poner en antecedentes de la falta a las autoridades académicas e institucionales según la filiación declarada (8).

Revistas chilenas han sido sorprendidas por casos de deshonestidad que han sido comunicados a sus lectores (10), y la Revista Chilena de Obstetricia y Ginecología no ha sido la excepción; es así que desde el año 2004, en dos oportunidades se detectó plagio en el proceso de evaluación editorial de manuscritos enviados para publicación, debiéndose detener el proceso. Manuscritos publicados en nuestra revista también han sido plagiados, habiéndose iniciado el reclamo al editor de la revista respectiva y la información a las autoridades académicas, científicas e institucionales declaradas por el autor responsable.

Es objetivo de la Sociedad Chilena de Obstetricia y Ginecología recuperar la indización en la National Library of Medicine, en la que estuvimos presentes hasta 1995 (11). Para lograrlo, entre otras cosas, debemos asegurar a nuestros lectores que los manuscritos son fidedignos, y que cumplen con todos los requisitos éticos de las publicaciones biomédicas (12).

El deseo de publicar experiencias clínicas, investigaciones originales, revisiones de la literatura, etc., debe ser consecuencia de la verdadera vocación científica y docente del médico, regulados por la ética y el método científico, y no por la necesidad curricular o la vanidad profesional.

\section{Dr. ENRIQUe Donoso SiÑA} Editor Jefe. Revista Chilena de Obstetricia y Ginecología. 


\section{REFERENCIAS}

1. Universidad Diego Portales. Disponible en: http:// www.udp.cl/investigacion/fondosestimulos/ publicacionesisi.htm

2. Universidad de Chile: Disponible en: http:// www.uchile.cl/uchile.portal?_nfpb=true\&_ pageLabel $=$ conUrl\&url $=5300$

3. Universidad Andrés Bello. Disponible en: http:// www.unab.cl/sitio-html/investigacion/ publicaciones_2006.asp

4. Pontificia Universidad Católica de Chile. Disponible en: http://www.puc.cl/dipuc/html/frameinves.htm

5. Comisión Nacional de Investigación Científica y Tecnológica. Disponible en: http://www.conicyt.cl/ fondecyt/concursos.html

6. Gálvez M. Publicaciones Biomédicas: realidad de Chile y Latinoamérica. Rev Chil Radiol 2006;12(3): 113-7.
7. Reyes H, Kauffmann R, Andersen M. La autoría en los manuscritos publicados en revistas biomédicas. Rev Méd Chile 2000;128(4):363-6.

8. Comité Internacional de Directores de Revistas Médicas. Requisitos uniformes para preparar los manuscritos que se presentan a las revistas biomédicas: redacción y edición de las publicaciones biomédicas. Rev Chil Obstet Ginecol 2004;69(2): 157-82.

9. Reyes H. El "factor de impacto" y el impacto de las revistas médicas. Rev Méd Chile 1998;126:135-8.

10. Reyes H, Palma J, Andresen M. Ética de las publicaciones en revistas médicas. Rev Méd Chile 2007; 135(4):529-33.

11. Donoso E. Revista Chilena de Obstetricia y Ginecología: volver a Index Medicus ¿una utopía? REV ChIL OBstet Ginecol 2006;71(1):1-2.

12. Reyes $\mathrm{H}$. Honestidad y buena fe: dos pilares en la ética de las publicaciones biomédicas. Rev Méd Chile 2007;135(4):415-8. 